\title{
Emerging Opportunities in Higher Education: Applied Behavior Analysis and Autism
}

\author{
Shahla Ala'i-Rosales ${ }^{1}$, Lise Roll-Pettersson², Sarah Pinkelman ${ }^{3}$, and Traci Cihon ${ }^{1}$ \\ ${ }^{1}$ University of North Texas, ${ }^{2}$ Stockholm University \& Akershus University College, and ${ }^{3}$ University of Oregon
}

\begin{abstract}
The growing number of children diagnosed with autism and the recognized importance of evidencebased interventions has substantially increased the need for well-trained applied behavior analysts. Relative to public/consumer demand, there are very few higher education programs that are equipped to train behavior analysts specializing in autism. Worldwide, there are only a few programs accredited by Association for Behavior Analysis International (ABAI), that have course sequences approved by the Behavior Analysis Certification Board (BACB), and have formal institutional course approval for classes in autism and behavior analysis. The purpose of this paper is to introduce a series of expert commentary on the context, content and systems required to build quality higher education programs in autism and applied behavior analysis. Together the articles in this special section of the European Journal of Applied Behavior Analysis form a resource for faculty and university administrators interested in the development of innovative and socially relevant training programs in higher education.
\end{abstract}

Key words: applied behavior analysis, higher education, autism

The Center for Disease Control (CDC, 2007) recently identified the increase in autism as an "urgent public health concern" (2007). In an analysis of epidemiological studies across time and cultures, Fombonne (2005) noted an increase in prevalence figures within the last 20 years: between 1966 and 1993 the median prevalence figure was 4.7 per 10,000 and in the period between 1994 and 2004, the median rate was 12.7 per 10,000 . In 2007, The CDC Autism and Developmental Disabilities Monitoring Network reported that approximately 1 in 150 8-year-old children in various areas of the United States had an Autism Spectrum Disorder. Similar international figures have been reported. For example, in Sweden reports indicate prevalence of 6.2 in 1000 children (Fernell \& Gillberg, 2010) and in China rates of 16.1 per 10,000 (Wong \& Hui, 2008). Across the globe, it is agreed that growing societal awareness, better detection,

A Behavior Analysis Online grant from the University of North Texas supported preparation of this manuscript. Correspondence may be directed to Shahla.Alai-Rosales@unt.edu or to Lise.roll-pettersson@specped.su.se. and broadening of diagnostic criteria contribute to the increase in the number of children diagnosed with autism (e.g., Rutter, 2005).

At this point in time, there is no known cause, and no known cure for autism (Geschwind, 2009). There are, however, a number of procedures and treatment models derived from the field of Applied Behavior Analysis (ABA) that are effective in teaching important skills, reducing challenging behavior and dramatically improving the quality of life for people with autism (c.f., Meyers \& Johnson, 2007; National Standards Project, 2009). Unfortunately, there is an alarming shortage of people trained to understand, implement and individualize these procedures (c.f., McGee \& Morrier, 2005; Scheurmann, Webber, Boutot, \& Goodwinl, 2003).

The increase in cases of autism combined with the shortage of trained ABA professionals constitutes a serious problem for individuals with autism, their families and for society. It is estimated that the financial costs associated with untreated or ineffectively treated individuals range from $\$ 656,000$ to $\$ 2.5$ million over the course of 
a lifetime (Jacobson, Mulick, \& Green, 1998; Jarbrink \& Knapp, 2001) and can cost at least $\$ 208,500$ per child during eighteen years of schooling (Chasson, Harris, \& Neely, 2007). Such estimates do not even begin to factor the human costs and suffering faced by people with autism and their families. Multiply such costs by the estimated number of individuals across the globe that are not receiving treatment and an "urgent health concern" becomes a crisis.

Generally, societal agencies, such as institutions of higher education, only allocate their limited resources to new activities when there is a crisis. In a crisis the contingencies result in immediate pressure to "change" in some way in order to avoid aversive stimulation or to increase access to reinforcement (Risley, 2001). Within higher education, the crisis contingencies will likely involve resource allocations, rankings and accreditations, and complaints or praise by important constituencies. If behavior analysts are able to help universities gain access to reinforcement to avoid aversive stimulation, crisis treatment availability in combined with global movements in higher education present higher educators in behavior analysis with some promising opportunities for the training of applied behavior analysts.

For example, increased funding is available to institutions of higher education for training autism personnel in the behavioral treatment of autism, to conduct research to study the effectiveness of interventions, and for training leadership personnel with strong behavior analytic skills (c.f., US National Institutes of Health, 2010). There is also an increasing public demand for trained behavior analysts (and strong complaints when they are not available), particularly in the area of early intervention. In many places, governmental or third party health care coverage is increasing (e.g., Bouder, Spielman, \& Mandell, 2009). Furthermore, graduate programs that enable students to sit for certification are growing at an unprecedented rate (Hughes \& Shook, 2007). Demand and funding create opportunities for university faculty. Under such conditions, faculty and administrators have leverage created by societal need to support bold program creations and innovations.
There is another movement that may be of importance to behavior analysts in higher education: Universities are increasingly being called upon to justify their activities as socially relevant (e.g., Association of American Colleges and Universities, 2007; European Association for Quality Assurance in Higher Education, 2010). Towards that end, leaders in European higher education emphasize the contributions of flexible and dynamic "knowledge triangles", that is, the beneficial interactions and outcomes that can occur between education, research and innovation (Jacobsson, 2009). In the summary statement of a recent conference supported by the European Commission, the conveners stated that under conditions of crisis the funding of higher education, especially research and innovation should be increased rather than reduced. This would be particularly true when the "triangle" being funded involves close partnerships and innovative problem solving between universities and industry (Jacobsson, 2009). Furthermore, the premium is on applied rather than theoretical research and on efforts and resource allocations that meet modern demands on higher education (Nayyar, 2008). Higher education is in search of creative and adaptable ways to survive and to respond to the crises presented by a world in constant cultural and technological disruption.

This, too, is a leverage point for program developers. Since its inception, Applied Behavior Analysis has engaged in bold actions to predict and produce behavior change that results in meaningful and valued outcomes. From the beginning, this scientific experimental approach has produced innovative ways of exploring, understanding, and improving the human condition (c.f., Baer, Wolf \& Risley, 1968/1987; Goldiamond, 1965; Lutzker \& Martin, 1981). The motivating operations in place for creative advances in higher education programs in Applied Behavior Analysis and autism. It was the recognition that the present conditions are opportunities that led to, first, the "Texas Summit" and second, the completion of this special section. During the process of teaching and striving to improve the education of behavior analysts we can develop new methodologies and innovations in both higher education and in autism intervention. 


\section{Convening Participants: The Texas Summit}

It is our hope that as conditions unfold within institutions of higher education around the world, the faculty in departments of behavior analysis or related disciplines will have resources to create or expand programs. This special section is an effort towards that end. In September of 2010, a group of area experts, stakeholders and generalists were invited to contemplate, discuss and debate matters related to the training of autism interventionists. We specifically asked some of the participants to prepare thoughtful commentary regarding targeted areas: professional expectations, content matter, and higher education methods. These were people that had demonstrated mastery and expertise in the area they were asked to address. Other participants, parents of people with autism and students in graduate programs in autism, were asked to listen to presentations, meet and consort with those providing commentary and to formally and informally give the summit organizers (the authors) feedback on the topics addressed.

The "Texas Summit" convened for two days, involving presentations and large and small group discussions. After the meeting, each area expert was asked to formally submit a manuscript for inclusion in this special section. Each manuscript underwent a peer review process by at least two scholars with area expertise. What the reader views in this special section is the culmination of the contributions of the area experts, the stakeholders, and the peer reviewers.

\section{Professional Expectations}

The first two articles provide the reader with an understanding of professional knowledge and performance expectations in the field of behavior analysis and autism. Weiss and Shook (this issue) present an overview of the development and process of identifying knowledge and skills documented to be important for behavior analysts specializing in autism interventions. The authors very eloquently describe the need to protect consumers from unskilled or inappropriate interventions. They suggest one of the most important avenues to insure benefit and prevent harm is through comprehensive and high quality training requirements and certification of behavior analysts. Weiss and Shook describe inventories of educational experiences developed by the Association for Behavior Analysis International (ABAI), the ABAI Autism Special Interest Group, and the Behavior Analysis Certification Board (BACB). It should be noted that these inventories have served as a guide for the handful of programs already offering some degree of specialized training in behavior analysis and autism. For example, Table 1 provides an overview of the graduate curriculum in the Department of Behavior Analysis at the University of North Texas. In it are the core curricular content areas required by $\mathrm{ABAI}$ and the $\mathrm{BACB}$ as well as the course and performance content recommended by the ABAI Autism SIG. The work described by Weiss and Shook provides a blueprint for building this kind of curriculum in basic principles and practices of behavior analysis as they apply to autism intervention.

Green (this issue) extends Weiss and Shook by offering a point of emphasis that is inherent in the world view of behaviorism but that is frequently neglected in the arena of professional training: "scientific attitude". That is, Green presents a clear argument for strengthening the role and practice of scientific method in higher education training of interventionists. This is especially true in a climate where both valid research and quackery are proliferating at exponential rates. The newly educated behavior analyst must be trained to discriminate, navigate, and evaluate claims and findings in ways that will rely on scientific knowledge and inquiry. In this way, as they make decisions about what and how to intervene, they will do so with a greater degree of integrity and assurance.

\section{Curricular Content}

With regard to curricular content, two areas required special attention: 1) skills students can learn to effectively support families and 2) skills required to implement and supervise Early and Intensive Behavioural Interventions (EIBI). Both of these areas have a growing research base. They are also two areas where the consequences are profound. 
Table 1. A Curricular Example

\section{University of North Texas, Department of Behavior Analysis}

Core BA Curriculum
Autism Specialty Area

\section{Required Courses}

Required Courses

- BEHV 5000 Observation and Measurement of Behavior and Environment

- BEHV 5100 Respondent and Operant Conditioning

- BEHV 5010 Experimental Analysis of Behavior

- BEHV 5020 Theory and Philosophy in Behavior Analysis

- BEHV 5140 Research Methods in Behavior Analysis

- BEHV 5150 Techniques in Applied Behavior Analysis

- BEHV 5250 Quantitative Methods in Behavior Analysis

- BEHV 5250 Stimulus Control

- BEHV 5250 Functional Analysis

- BEHV 5330 Verbal Behavior

- BEHV 5540 Legal, Ethical and Professional Issues in Behavior Analysis

- BEHV 5560 Development of Behavior Intervention Programs

- BEHV 5570 Training and Supervision of Staff in Human Service Settings

Children and their families can suffer or flourish as a result of the quality of intervention. The two articles in this part are designed to provide the reader with curricular directions that should target interventionist skills that result in high quality interventions.

Mayville and Letso (this issue) provide a description of content specific knowledge and skills related to families and to community participation across the lifespan. This includes information on training domains, assessment and intervention goals, behavior
- BEHV 5028 Applied Behavior Analysis \& Autism: Methodological and Conceptual Issues

- BEHV 5029 Applied Behavior Analysis \& Autism: Research and Practice

\section{Performance Requirements}

- BEHV 5810 Practicum in Autism I

- BEHV 5815 Practicum in Autism II

- BEHV 5815 Practicum in Autism III

- BEHV 5820 Internship in Autism

- BEHV 5950 Thesis in Autism

Professional Portfolio

Area Descriptions

Work Samples

Supervisory Evaluations

Self Evaluations

\section{Elective Courses}

Additional courses within the

Department of Behavior Analysis and

across the university (e.g.,

Instructional Design, Child

Development, Organizational

Behavior Management, Behavioral

Pharmacology, Applied

Anthropology)

change procedures, and the identification and management of variables affecting meaningful family and community life. As they remind us, the question, "Does what we are teaching matter?" is most profoundly apparent in the context of a person's family and community. They offer suggestions as to how our students can identify and address valued outcomes (by the person with autism, the family, and the community). They present this information within a lifespan perspective, covering early childhood to adulthood. 
One area within the lifespan, early childhood, warrants extended attention. An increasingly robust body of research supports EIBI. However, behavior analysts with sophisticated and complex repertoires produced the dramatic findings demonstrated in EIBI research. In this part, one of those researchers, Eikseth, describes the array of theoretical and clinical knowledge that a well-trained EIBI professional should have in order to produce outcomes similar to those found in the EIBI research. As he points out, the task analysis of what to train students in higher education is still largely experiential rather than evidence-based. However, it is also important to note that evidence-based practice is the combination of research evidence and clinical wisdom (Geddes \& Harrison, 1997). Until there are more studies of the professional training curriculum targets, the clinical wisdom of highly experienced scientist-practitioners will provide us with an advantageous starting point.

\section{Higher Education Methods}

While the first two parts present a landscape of "what" to train future interventionists, the final part provides the reader with perspectives and information on "how" to train. Three vantage points were included here: utilizing technology, performance engineering, and promoting faculty excellence.

First, Roll-Petterson, Alai-Rosales, Keenan and Dillenburger (this issue) provide us with an overview of how new technologies can improve the quality and effectiveness of higher education training programs. This includes blended use of media, distance, and engineering technologies to establish and maintain behavioral repertoires for students in university settings. The number and types of new technologies available are astonishing and bring promise of accessible and effective education for many, many behavior analysts. Roll-Petterson and colleagues stress that the foundational elements of good university instruction (humane, student centered, outcome based teaching) be held at the forefront as faculty learn to incorporate an increasingly diverse and large number of new technologies. They also point out that the technologies hold promise for both essential knowledge and intervention performance.
Ingvarsson, Cammileri and Smith (this issue) provide us with a detailed analysis of the systems and techniques that produce reliable and high quality performances in adult learners. The authors describe the theory and research on establishing and maintaining repertoires in behavior analysts serving children with autism and their families. They articulate the importance of providing performancebased training to students in higher education. Performance-based training presents unique challenges to higher education, as the procedures to produce these repertoires are typically not found in lecture halls. Fortunately, the authors provide a wealth of resources documenting effective methods and systems that do provide high quality performance-based training.

These first six articles provide new or developing programs rich resources for the standards and content of training curricula for advanced professional training in behavior analysis and autism intervention. Our final article by Bernstein and Dotson (this issue) speaks specifically to the faculty member and offers clarifications and suggestions for promoting teaching excellence. They begin with a description of the levels of understanding that are required of behavior analysts working in autism intervention and then examine pedagogical methods that have been shown to produce some of these repertoires. They place a special emphasis on teaching "deep understanding" and flexible and adaptive problem solving skills that produce innovators and contributors to effective and meaningful autism interventions. They end with a call to increase scholarly examination of teaching practices by providing descriptions and results that are visible to other higher educators within and outside of behavior analysis.

\section{Ongoing Dialogues}

Throughout the Texas Summit and the activities leading up to this special section we have asked colleagues to discuss, comment, criticize, as well as review article drafts. As with any scientific discipline some inner contemporary tensions and challenges emerged. 
The inclusion of inner disciplinary dialogues is an important component to achieving critical thinking skills, deep understanding, and problem solving in higher education. Instructors can use these dialogues to help students understand how the content they are learning fits with other sources of knowledge and action. Three specific topics repeatedly surfaced amongst summit participants: disciplinary identity, interdisciplinarity, and globalization.

\section{Disciplinary Identity}

What is ABA? A source of tension exists about our disciplinary identity. Within this discussion it is helpful to understand how disciplines as a general class are defined. In the broadest sense, they are self-referential communities, evolving for the purpose of establishing rules for inclusion in a specific community, for delineating the subject matter of that community, for instructing the methods of inquiry, and for describing the approaches to training within the disciplinary culture (Weingart, 2010). Of course, the boundaries of any given discipline are subject to change and evolution and, while a discipline may be viewed from the outside as a coherent whole, internal debates about what gets included and what does not get included often occur (Frodeman, 2010). For these reasons we would like to talk about the general definitions of ABA and then point out some of the contemporary tensions.

As we understand it, ABA is a branch of a natural science, behavior analysis, which studies behavior-environment interactions. In the case of ABA, the methods of scientific inquiry valued by the broader disciplinary community are employed as a means to understanding and improving conditions for humans and other living creatures. ABA is characterized by: 1) directly observable and quantifiable subject matter; 2) evidence that experimental intervention variables are reliably effective in changing socially important behaviour; 3) operational descriptions of behaviours and procedures; 4) conceptually coherent integration of procedural findings with basic principles and knowledge of behaviour (Baer, Wolf, \& Risley, 1968). The content areas of ABA are broad and diverse and include autism as well as many other content areas of importance. For example, behavior analysts have conducted work in the areas of environmental sustainability (e.g., Lehman \& Geller, 2004), behavioral medicine (e.g., Wadden \& Foster, 2000), industrial safety (e.g., Mattilla, Rantanen \& Hyttinen, 1994), equine care (Ferguson \& Rosales-Ruiz, 2001), sports psychology (e.g., Lacy \& Goldston, 1990), and, of course, autism intervention (e.g., Matson \& Smith, 2008).

Where do the tensions lie? There are at least two sources of difficulty. While some version of the above is what many applied behavior analysts might describe, one tension appears to be about the way we talk about ABA. Many Summit participants report an increase in talking and acting about $\mathrm{ABA}$ as if it is an intervention procedure rather than a scientific process. For example, a casual search of the Internet will reveal many instances of equating $\mathrm{ABA}$ with a particular set of procedures or models (usually discrete trial instruction with children with autism) and having limited generality (such as ABA is only for particular learners). Some of this verbal behavior emanates from non-professionals, but also appears to be demonstrated by people who have completed higher education training programs in the discipline. Furthermore, there are cases of litigation (e.g., Choutka, Doloughty, \& Zirkel, 2004) and scholarly commentaries in journals (e.g., Callhan, Shukla-Mehta, Magee, \& Wie, 2010) in which the relative merits of doing "ABA" versus a particular model or procedure have been argued. In keeping with Baer, Wolf and Risley (1968), we would not "do ABA" in an intervention, per se. $A B A$ is an applied science, a process, which allows us to discover what procedures or collections of procedures are effective or not effective.

It is not clear why there is confusion about the nature of ABA. Is it hard to describe a process? Is marketing or counter marketing responsible for the change in the way our discipline is described? Or, is our discipline in the process of redefining itself? 
Whatever the reason, the tension and the possible ways of communicating about it and understanding it is important and should be directly addressed in our disciplinary training programs.

Along the same lines, the relationship between our science and our practice has risen to a boiling point, as illustrated by a recent ABAI presidential column. In this commentary, Friman (2010) reflects on recent events and ponders the status of $\mathrm{ABAI}$ as a science organization, the possibilities of it an evolving into a practice-based organization, and the need to safeguard the science of behavior analysis. He goes on to suggest that one of the more important activities of ABAI is to ensure, through the accreditation process, that science is an important part of behavioral educational curricula; in fact, "science and education are handmaidens to each other, and both serve and shape practice" (5). The tension is not a new one. It is part of the reason for the larger movement of scientist-practitioner models that began with the 1949 Boulder conference (Baker \& Benjamin, 2000), and was central to public debates within behavior analysis in the 1980s (see Baer, 1981; Malott, 1981; Michael, 1980) and the 1990s (Baer, 1992; Johnston, 1996; Malott, 1992; Reid, 1992). This topic, too, will require surveillance and inclusion within behavioral higher education programs.

\section{Interdisciplinarity}

Autism is a pervasive disorder that affects every part of life (American Psychiatric Association, 1994; World Health Organization, 2007). This means that, by necessity, many other disciplines will be involved in providing services to people with autism and their families. Furthermore, many other disciplines will be involved in trying to understand and solve the puzzle of autism. For the behavior analysts in training, this means that for the well-being of the people we serve we must find productive ways of collaborating and working with other disciplines (Idol, Nevin, \& Paolucci-Whitcomb, 1994). There was frequent discussion among Summit participants regarding the importance and the difficulty that this entails.
The taxonomies of interdisciplinarity are numerous and evolving (Klein, 2010). Two types of interdisciplinarity will be described here: casework and communication (Krohn, 2010). Interdisciplinary casework involves activities related to solving specific problems (e.g., a speech language pathologist and a behavior analyst designing a communication intervention). Interdisciplinary communication involves information sharing and stimulation between researchers and/or practitioners devoted to a particular area (e.g., early identification of autism might involve behavior analysts, speech pathologists, pediatricians, nurses, public health professionals, etc.). Such collaborations are increasingly important and useful. In any case, the skills needed to successfully participate in these venues are teachable and important to include in professional training programs (Chen, Klien \& Minor, 2009).

\section{Globalization}

We live in an age of disruption and constant change. Recognized by universities all over the world, this fact requires contemplation and innovative actions on the part of higher education (Nayyar, 2008). It also requires self-awareness in terms of how one's discipline and work fit within the greater context of globalization. There appear to be at least three main points here: 1) Behavior analysis is a collective science with wide generality across cultures and content areas; 2) from its inception, behavior analysis has placed itself within the values of global sustainability and humane outcomes (Skinner, 1953); and 3) there are methods to effectively increase collaborations across cultures and we can teach our students to do this (Karlburg, 2010). At this point in time, we are presented with an opportunity to support the science of behaviour on a global level (Hughes \& Shook, 2007). The Texas Summit and the resulting special section are perhaps one indicator that training efforts will contribute to some level of global generality. Participants were professionals and students from diverse parts of the world. Many of them spoke to both the strengths and difficulties of implementing behavioural interventions within and across different cultures. 
This included issues related to access to services (very limited in some parts of the world), training content (sometimes culturally incongruent goals and methods), and resources (limited or disciplinarily restricted funds).

As we engage in efforts such as this Summit, we make progress. We are forming culturally adaptive curriculum content, are using technologies to increase access and address disparities, are refining methods to effectively teach that curriculum and are having international dialogues about how that fits with what else we know. This special section of The European Journal of Behavior Analysis reflects one of several actions designed to move our training and our meaningful global impact one step further.

\section{References}

American Psychiatric Association (1994). Diagnostic and Statistical Manual of Mental Disorders. Washington, DC: American Psychiatric Association.

Association of American Colleges and Universities, The National Leadership Council for Liberal Education and America's Promise. (2007). College Learning for the New Global Century. Washington, DC: Association of American Colleges and Universities.

Baer, D. M. (1992). Teacher proposes, student disposes. Journal of Applied Behavior Analysis, 25, 89-92.

Baer, D. M., Wolf, M. M.\& Risley, T. R. (1968). Some current dimensions of applied behavior analysis. Journal of Applied Behavior Analysis, 1, 91-97.

Baer, D.M (1981). A flight of behavior analysis. The Behavior Analyst, 4, 85-91.

Baker, D.B. \& Benjamin, L.T. (2000) The affirmation of the scientist-practitioner, American Psychologist, 55, 241-246

Bernstein and Dotson (2010) Promoting Teaching Excellence in Professional Education of Behavior Analysts, European Journal of Behavior Analysis, 11, 277-288

Bibby, P., Eikeseth, S., Martin, N. T., Mudford, O. C., \& Reeves, D. (2001). Progress and outcomes for children with autism receiving parent-managed intensive interven- tions. Research in Developmental Disabilities, 22, 425-447

Bouder, J.N., Spielman, S. \& Mandell, D.S. (2009) Brief report: Quantifying the impact of autism coverage on private insurance premiums, Journal of Autism and Developmental Disorders, 39, 953-957.

Callhan, K. Shukla-Mehta, S. Magee, S. \& Wie, M. (2010) ABA versus TEACCH: the case for defining and validating comprehensive treatment models in autism. Journal of $A u$ tism and Developmental Disorders, 40, 74-88.

Centers for Disease Control and Prevention. Surveillance summaries. MMWR Morbidity and Mortality Weekly Report. 2007;56(SS1): $1-28$

Chasson, G., Harris, G., \& Neely, W. (2007). Cost comparison of early intensive behavioral intervention and special education for children with autism. Journal of Child and Family Studies, 16, 401-413.

Chen, D., Klein, D., \& Minor, L. (2009). Interdisciplinary perspectives in early intervention: Professional development in multiple disabilities through distance education. Infants \& Young Children, 22(2), 146-158.

Choutka, C.M., Doloughty, P.T., \& Zirkel, P.A. (2004) The "Discrete Trials" of Applied Behavior Analysis for Children with Autism: Outcome-Related Factors in the Case Law, Journal of Special Education, 38, 95-103.

Crozier, F., Costes, N., Ranne, P., \& Stalter, M. European Association for Quality Assurance in Higher Education. (2010). Enqa: 10 years (2000-2010) a decade of European co-operation in quality assurance in higher education. Helsinki, Finland: European Association for Quality Assurance in Higher Education.

Eikseth, S. (2010) Examination of Qualifications Required of an EIBI Professional. European Journal of Behavior Analysis, 11, 239-246

Ferguson, D. L. \& Rosales-Ruiz, J. (2001) Loading the problem loader: The effects of target training and shaping on trailer loading behavior of horses. Journal of Aplied Behavior Analysis, 34, 409-424.

Fernell, E., \& Gillberg, C. (2010). Autism 
spectrum disorder diagnoses in Stockholm preschoolers. Research in Developmental Disabilities, 31, 680-685.

Fombonne, E. (2005). Epidemiological studies of pervasive developmental disorders. In F. Volkmar, R. Paul, A. Klin, \& D. Cohen (Eds.), Handbook of Autism and Pervasive Developmental Disorders (pp. 42-70). Hoboken, NJ: John Wiley \& Sons.

Friman, P. (2010, August). The president's column. Association for Behavior Analysis International, Newsletter 2(2), 2-5.

Frodeman, R. (2010). Introduction. In R. Frodeman (Ed.), The Oxford Handbook of Interdisciplinarity (pp. xxix-xxxix). New York, NY: Oxford University Press.

Frodeman, R., Thompson-Klein, J., Mitcham, C., \& Holbrook, B. (2010). The Oxford Handbook of Interdisciplinarity. New York, NY: Oxford University Press.

Geddes, J. R. \& Harrison, P. J. (1997). Closing the gap between research and practice. British Journal of Psychiatry, 171, 220-225.

Geschwind, D. (2009). Advances in autism. Annual Review of Medicine, 60, 367-380.

Goldiamond, I., Dyrud, J.E. \& Miller, M.D. (1965). Practice as research in professional psychology. The Canadian Psychologist, 6, 110-128.

Green, G. (2010) Training Practitioners to Evaluate Evidence About Interventions. European Journal of Behavior Analysis, 11, 223-228

Hughes, J. C., \& Shook, G. (2007). Training and certification of behaviour analysts in europe: past, present, and future challenges. European Journal of Behavior Analysis, 8(2), 239-249.

Idol, L., Nevin, A., \& Paolucci-Whitcomb, P. (1987). Collaborative Consultation. Austin, TX: PRO-ED Inc.

Ingvarsson, E. Cammileri, A. \& Smith, C. (2010) University Training to Prepare Autism Specialists: Behavior Analysis and Performance-Based Change, European Journal of Behavior Analysis, 11, 261-276

Jacobson, J.W., Mulick, J. A., \& Green, G. (1998). Cost-benefit estimates for early intensive behavioral intervention for young children with autism: General model and single state case. Behavioral Interventions, 13, 201-226.

Jacobsson, G. (2009). Proceedings of the knowledge triangle: shaping the future of Europe. Stockholm: Swedish National Agency for Higher Education.

Jarbrink, K., \& Knapp, M. (2001). The economic impact of autism in Britain. Autism, $5,7-22$.

Johnson, J.M. (1996). Distinguishing between applied research and practice. The Behavior Analyst, 19, 35-47.

Karlberg, M. (2010). Education for interdependence: the university and the global citizen. The Global Studies Journal, 3(1), 129-138.

Krohn, W. (2010). Interdisciplinary cases and disciplinary knowledge. In R. Frodeman (Ed.), The Oxford Handbook of Interdisciplinarity (pp. 31-50). New York, NY: Oxford University Press.

Lacy, A.C. \& Goldston, PD. (1990) Behavior analysis of male and female coaches in high school girls' basketball. Journal of Sports Behavior, 13, 29-39

Lehman, P.K. \& Geller, E.S. (2004) Behavior analysis and environmental protection: Accomplishments and Potential for More. Behavior and Social Issues, 13, 13-32

Lutzker, J.R. \& Martin, J.A. (1981). Behavior Change. Monterey: Brooks/Cole.

Malott, R. (1981). In response concerning Michael's concerns. The Behavior Analyst, 4(2), 163-164.

Malott, R. W. (1992). Should we train applied behavior analysts to be researchers? Journal of Applied Behavior Analysis, 25, 83-88.

Matson, J. L., \& Smith, K. R. M. (2008). Current status of intensive behavioral interventions for young children with Autism and PDDNOS. Research in Autism Spectrum Disorders, 2, 60-74.

Mattilla, M. Rantanen, E. \& Hyttinen, M. (1994) The quality of work environment, supervision and safety in building and construction. Safety Science, 17, 257-268.

Mayville, E. A. and Letso, S. (2010) Family and community curricular content for training in applied behavior analysis and autism, 
European Journal of Behavior Analysis, 11, 229-237

McGee, G., Morrier, M. (2005). Personnel Preparation. In Volkmar, F.R., Rhea, P., Klin, A., Cohen, D. (Eds.) Handbook of Autism and Pervasive Developmental Disorders, Vol. 2: Assessment, interventions, and policy (3rd edition). Hoboken, NJ: John Wiley \& Sons.

Michael, J.L. (1980). Flight from behavior analysis. The Behavior Analyst, 3, 1-21.

Myers, S.M. \& Johnson, C. P. (2007) Management of children with autism spectrum disorders. American Academy of Pediatrics, 120,1162-1182

National Research Council (2001). Educating Children with Autism. Washington D.C: National Academy Press.

National Standards Project Report (2009) National Autism Center, Retrieved November 2, 2010 from: www.nationalautismcenter. org/affiliates/

Nayyar, D. (2008) Globalization: What does it mean for higher education? In L.E. Weber \& J.J. Duderstadt (Eds.), The Globalization of Higher Education (pp. 3-14). London: Economica Ltd..

Reid, D. H. (1992). The need to train more behavior analysts to be better applied researchers. Journal of Applied Behavior Analysis, 25, 97-99.

Risley, T. (2001). Do good, take data. In W. Donahue, D. Henderson, S. Hayes, J. Fisher, \& L. Hayes (Eds.), A History of the Behavioral Therapies (pp. 267-287). Reno, NV: Context Press.

Roll-Petterson, L., Alai-Rosales, S., Keenan, M., and Dillenburger, K., (2010). Teaching and learning technologies in higher education: Applied behaviour analysis and autism; "Necessity is the mother of invention".
European Journal of Behavior Analysis, 11, 247-259

Rutter, M. (2005). Incidence of autism spectrum disorders: changes over time and their meaning. Acta Paediatrica, 94, 2-15.

Scheuerman, B., Webber, J., Boutot, E., \& Goodwin, M. (2003). Problems with personnel preparation on autism spectrum disorders. Focus on Autism and other Developmental Disabilities, 18(3), 197-206.

Skinner, B.F. (1953). Science and Human Behavior. New York : Macmillan.

Thompson-Klein, J. (2010). A taxonomy of interdisciplinarity. In R. Frodeman (Ed.), The Oxford Handbook of Interdisciplinarity (pp. 15-30). New York, NY: Oxford University Press.

Wadden, T. A. \& Foster, G. D. (2000). Behavioral treatment of obesity. Medical Clinics of North America, 84, 441-461.

Weingart, P. (2010). A short history of knowledge formations. In R. Frodeman (Ed.), The Oxford Handbook of Interdisciplinarity (pp. 31-50). New York, NY: Oxford University Press.

Weiss, M.J. \& Shook, G. (2010) Resources on training requirements for applied behavior analysts: The Behavior Analyst Certification Board and the Autism Special Interest Group Consumer Guidelines, European Journal of Behavior Analysis, 11, 217-222

World Health Organization. (2007). "International Statistical Classification of Diseases and Related Health Problems 10th Revision Version for 2007" (web). World Health Organization. Retrieved November 2, 2010 http://apps.who.int/classifications/apps/icd/ icd10online/

Wong, V., \& Hui, S. (2008). Epidemiological study of autism spectrum disorder in China. Journal of Child Neurology, 23(1), 67-72. 